\title{
LIMITES E CONTROVÉRSIAS DA IMPLANTAÇÃO DE POLÍTICAS PARA A EXPERIÊNCIA DO PROGRAMA NACIONAL DE INCLUSÃO DE JOVENS (PROJOVEM) NO MUNICÍPIO DE SÃO PAULO
}

\author{
Sílvia da Silva Craveiro* \\ Maria Paola Ometto**
}

\begin{abstract}
Resumo: O trabalho discute a implantação de políticas públicas para juventude, especificamente o ProJovem no município de São Paulo de 2006-2007. São analisados elementos, identificados na literatura, que recorrentemente dificultam a implantação e os resultados dessas políticas: a falta de conexão entre as políticas para juventude dos três níveis de governo, a participação insuficiente dos próprios jovens e a sua segmentação como em "situação de risco". Todos esses elementos estão presentes nessa experiência, apesar da intenção do governo federal de realizar uma política intersetorial, integrada e participativa. Os problemas relacionam-se com a inadequação da proposta às especificidades do município e com o pouco tempo de aprendizado para a execução do Programa.
\end{abstract}

Palavras-chave:juventude, política pública, implantação, intersetorialidade, ProJovem.

Abstract: The paper discusses the implementation of public policies for youth, the case of ProJovem in São Paulo. Three elements that repeatedly hinder the implementation and results of these policies are analyzed: low connection between the various public policies for youth from all levels of government, low participation of youth and their segmentation as "risk category". All these elements are present in this experience, despite the federal government's intention of an intersectoral and participatory policy. The main issues are related to the inadequacy of the proposal to the specificities of the

* Possui graduação e mestrado em administração pública pela EAESP/FGV. É doutoranda em administração pública e governo pela EAESP/FGV e atualmente é professora da Etec Cepam de Gestão Pública. E-mail: silviacraveiro@gmail.com.

** Possui graduação em administração pública pela EAESP/FGV, é mestre em administração pela UFPR e doutoranda em administração pública e governo pela EAESP/FGV. E-mail: paolaometto@hotmail.com. 


\section{Introdução}

O desenvolvimento de políticas públicas para a juventude no Brasil ganhou impulso nas últimas décadas e tornou-se central no debate de temas como desemprego e violência. A emergência do assunto como problema e sua entrada na agenda pública se deu no final dos anos 90. Sposito e Carrano (2003), ao analisarem as políticas públicas federais para juventude do Governo FHC (1995-2002), demonstram que a explosão da temática se dá no mandato de 1999-2002, com a criação de 18 programas na área, contra seis do mandato anterior. Corroborando os dados federais, há um crescimento das políticas públicas para jovens desde 1980 no âmbito municipal, passando de três ações do período de 19811984 para 166 entre 1997-2000 e 516 entre 2001-2004 (SPOSITO; SILVA; SOUZA, 2006).

Antes disso, os jovens eram abrangidos pelas políticas sociais destinadas a todas as faixas etárias. A especificação por grupo etário começou com as políticas para crianças e adolescentes, após a criação do Estatuto da Criança e do Adolescente (ECA) em 1990, sendo que as políticas para crianças eram preponderantes no início da década de 90 (LOPES; SILVA; MALFITANO, 2006). As primeiras ações voltadas especificamente para os jovens surgiram na área da saúde. Posteriormente, desenvolveram-se iniciativas para "tirar o jovem" da criminalidade e da violência. No final da década de 1990, com o aumento do desemprego juvenil, elaboram-se políticas de inclusão no mercado de trabalho, entre elas, as de capacitação profissional (SPOSITO; CARRANO, 2003).

Um dos programas mais recentes com esse objetivo é o ProJovem, criado pelo governo Lula em 2004. O público atendido era formado inicialmente por jovens de 18 a 24 anos que não estivessem matriculados nas escolas e não tivessem vínculos formais de trabalho, então considerados como o segmento mais 
vulnerável e menos assistido por políticas públicas específicas. Embora o Programa tenha sido formulado pelo governo federal, a sua implantação foi realizada pelos governos municipais, com recursos federais, em sua maioria.

Por meio da análise do ProJovem no município de São Paulo do início de 2006 ao início de 2007, período no qual houve a implantação das primeiras turmas do ProJovem na cidade, este artigo pretende apresentar e discutir o processo de implantação de políticas públicas para juventude. Mais especificamente, entender se os problemas das políticas públicas para juventude apontados na literatura são encontrados no ProJovem, um programa que se apresenta com uma proposta integradora, intersetorial e participativa. A escolha do município de São Paulo para a análise deve-se ao fato de que nesse município a implantação do ProJovem apresentou inúmeras dificuldades que apontam para os limites de um programa intergovernamental para juventude com esse desenho. Hoje o ProJovem é desenvolvido em duas frentes, o ProJovem Trabalhador e o ProJovem Adolescente, programas que serão explicados posteriormente. Segundo o site nacional do Programa, o ProJovem Trabalhador é implementado atualmente em São Paulo. Não se obteve informações sobre o ProJovem Adolescente.

O estudo está estruturado em quatro seções, incluindo esta introdução. A segunda parte consiste no referencial teórico utilizado, no qual discorremos sobre política pública e suas etapas, com ênfase na implantação e sobre políticas públicas para juventude. Na terceira seção, a metodologia é apresentada, seguida da descrição da análise. Por fim, são feitas considerações finais, destacando propostas de pesquisas futuras.

\section{Referencial Teórico}

A política pública pode ser entendida como o conjunto de decisões e ações para mudar ou manter determinada situação, sendo realizadas por autoridade formal legalmente constituída 
| 228 |

Limites e controvérsias da implantação...

(SARAIVA, 2006; SOUZA, 2006). Alguns autores discutem a divisão da política pública em etapas para propósitos teóricos, entendendo que não necessariamente os estágios ocorrem de forma linear. Normalmente, todas essas etapas são contempladas em uma política pública. Saraiva (2006), por exemplo, delimita as seguintes: agenda, formulação, implantação, acompanhamento e avaliação. O presente artigo foca sua análise na implantação do ProJovem.

Dentre os estágios apontados acima, a formulação e a avaliação são os mais pesquisados. Todavia, a implantação é prática crucial para a consecução dos objetivos das políticas públicas, sendo que os problemas não antecipados encontrados nessa fase representam obstáculos para o sucesso da política (SILVA; MELO, 2000; GRINDLE, 1992). Muitos organismos internacionais de desenvolvimento e financiamento adotam um modelo linear em que, após a formulação, a política é implementada (com ou sem sucesso); contudo esse processo é muito mais amplo e complexo, visto que envolve ambiguidade de objetivos e diversos atores, contextos, negociações e barganhas (GRINDLE, 1992).

Segundo Majone e Wildavsky (1995), na implantação ocorrem efeitos retroalimentadores que podem reformular e redefinir as políticas, sendo um mecanismo de transformação contínua, de redesenho das mesmas. Essa reformulação ocorre por vários motivos, entre eles o fato de os atores não possuírem todas as informações para a tomada de Michael Lipsky (1980) decisão na etapa da formulação, a interferência de problemas de natureza política durante a implantação, o surgimento de resistências e boicotes, entre outros. Assim, programas, planos, regulações existem "como potencialidades, e sua realização depende das qualidades intrínsecas e das circunstâncias externas" (MAJONE; WILDAVSKY , 1995, p. 144).

De acordo com os autores, na implantação ocorre também aprendizagem, evolução, adaptação e decisão política. Desse modo, eles conceituam a implantação como evolução: 


\begin{abstract}
(...) com eventos ocorrendo antes e (esperamos) continuando depois. Em cada ponto precisamos lidar com novas circunstâncias que nos permitem perceber diferentes potencialidades, em qual ideia de política estamos implementando. Quando agimos para implementar uma política, nós a mudamos. (MAJONE; WILDAVSKY, 1995, p. 150).
\end{abstract}

Também os atores responsáveis pela implantação são diversos, formando uma rede e criando a necessidade de coordenação. Os chamados "burocratas de nível de rua" aparecem como atores fundamentais no exercício de sua discricionariedade perante o público final. A expressão "burocratas de nível de rua" (street-level bureaucrats) foi criada por para designar os servidores públicos que interagem diretamente com os cidadãos, como policiais e assistentes sociais, e que, segundo o autor, "deveriam ser vistos como parte da comunidade de formulação das políticas". Além dos atores governamentais, destaca-se ainda o papel das organizações não-governamentais e dos demais stakeholders na execução das ações (SILVA; MELO, 2000).

\title{
2.1 As políticas públicas para a juventude
}

Sposito e Carrano (2003) afirmam que as políticas para os jovens possuem três pontos importantes a serem considerados: (a) a forma com que o Estado e a sociedade civil se relacionam, incluindo a participação da juventude nas políticas, (b) como o jovem é descrito nas políticas públicas e pela sociedade e (c) a baixa articulação entre as diversas políticas públicas dos três níveis governamentais.

$\mathrm{O}$ relacionamento entre Estado e sociedade civil para o desenvolvimento de ações voltadas para a juventude é fundamental, pois é a partir desse relacionamento que se pode considerar o jovem como protagonista das políticas, valorizando sua identidade e todas as suas especificidades. Contudo, nas 
políticas públicas para a juventude a participação dos jovens ainda é limitada. São poucos os espaços de participação nas ações.

O segundo item apontado por Sposito e Carrano (2003) diz respeito à necessidade de, durante a elaboração de uma política pública, entender e delimitar o que é juventude, implicando identificar um ciclo de vida. Essa delimitação não seria "apenas o retrato passivo de formas dominantes de conceber a condição juvenil, mas poderia agir, ativamente, na produção de novas representações" (SPOSITO; CARRANO, 2003, p.18). Histórica e socialmente, a juventude tem sido considerada uma fase de vida marcada pela instabilidade associada a determinados problemas sociais. Muitas são as ideias negativas sobre o jovem, principalmente do pobre, que é visto como vulnerável, em situação de risco, "menor infrator".

Em seu estudo das políticas públicas para juventude de 74 municípios de regiões metropolitanas brasileiras, Sposito, Silva e Souza (2006) demonstraram que as políticas estudadas estabelecem uma clivagem entre os programas para os adolescentes em situação de risco social e os que não estão em situação de risco. No estudo sobre as políticas federais do governo FHC (SPOSITO; CARRANO, 2003), é abordada a questão do tempo livre do jovem e de como preenchê-lo por meio da criação de atividades de esporte e cultura. O preenchimento desse tempo ocioso é considerado necessário, nas políticas estudadas, para que o jovem não se envolva com drogas e outras ações ilícitas. No que tange às políticas voltadas para combater o desemprego juvenil, o tema também aparece associado ao enfrentamento do crime e do tráfico "que arrebanha o jovem desocupado" (SPOSITO; SILVA; SOUZA, 2006).

Esses exemplos demonstram como as políticas para esse público veem a juventude como problema social, destacando a necessidade de controlar e disciplinar os jovens pobres, em situação de rua e em conflito da lei. Assim, as "iniciativas públicas devem prevenir ou conter a violência e as condutas de risco de jovens das camadas populares" (SPOSITO; SILVA; SOUZA 2006, p. 243). Essa abordagem prejudica a construção de políticas voltadas aos direitos dos jovens, à sua diversidade e atuação na sociedade. 
Adicionalmente, quando nos deparamos com as políticas públicas pesquisadas no âmbito federal no governo FHC e no âmbito municipal durante o governo Lula, existe uma diversidade de faixas etárias e concepções que definem a juventude. Isso causa uma desarticulação e dificulta a coordenação das políticas, pois as ações são fragmentadas e, embora deem espaço à inovação e experimentação, resultam em pouca efetividade e enfraquecem a construção de uma política pública integrada e mais ampla.

As políticas públicas específicas para a juventude ganharam impulso no governo FHC, mas permaneceram desintegradas. Com o intuito de gerar uma política para a juventude mais articulada, no mandato do Presidente Lula, em 2004, foi constituído grupo interministerial para a implantação de uma política nacional para a juventude, tendo como um dos pilares a criação de um programa nacional voltado para os jovens, denominado Programa Nacional de Inclusão de Jovens - ProJovem.

A partir de 2005, o ProJovem tornou-se componente estratégico da Política Nacional de Juventude do Governo Lula. Foi implantado sob a coordenação da Secretaria-Geral da Presidência da República em parceria com os Ministérios da Educação, do Trabalho e Emprego e do Desenvolvimento Social e Combate à Fome.

A meta do ProJovem era atuar em todas as 27 capitais brasileiras, atendendo a 400.000 jovens, no período de maio de 2005 a abril de 2007. Esse contingente representava cerca de $40 \%$ do universo de jovens de 18 a 24 anos das capitais e que estavam fora da escola. As prefeituras das 27 capitais seriam parceiras do Governo Federal na execução do Programa.

Além da estrutura de gestão e da perspectiva de abrangência nacional para atuar em parceria com as prefeituras, a proposta do ProJovem estabelecia uma abordagem pedagógica e de gestão intersetorial no âmbito local. O Programa tinha como finalidade proporcionar formação integral ao jovem, por meio da associação entre: elevação da escolaridade (conclusão do ensino fundamental), qualificação profissional e desenvolvimento de ações comunitárias. (BRASIL, 2005) 
| 232 |

Limites e controvérsias da implantação...

A partir de 2008 o ProJovem passa a ter um novo desenho. $\mathrm{O}$ "novo" ProJovem resultou da união de programas já existentes em nível federal e de reformulações consideradas necessárias de acordo com avaliação do modelo anterior. Atualmente, o ProJovem funciona a partir de dois formatos principais: O ProJovem Adolescente, voltado para o público de 15 a 17 anos, e o ProJovem Trabalhador de 18 a 29 anos (BRASIL, 2008). Houve modificações específicas no público-alvo, na carga horária, repasse de recursos, contudo o formato central de voltar-se para o público de maior vulnerabilidade e de manter o tripé elevação de escolaridade, qualificação profissional e ações cidadãs foi mantido.

\section{Metodologia}

A pesquisa sobre a implantação do ProJovem na cidade de São Paulo é de natureza qualitativa e caracterizada como descritiva, tendo em vista que descreve o processo de implantação de uma política e aponta os desafios decorrentes desse processo. A descrição é feita por meio de um estudo de caso, pois essa estratégia possibilita uma análise profunda de um determinado fenômeno (GODOY, 1995; MATIAS-PEREIRA, 2007).

Os dados foram coletados a partir de trinta relatórios gerenciais de implantação do Programa, do período de julho a dezembro de 2006, dentre outros documentos oficiais, e por meio de observação participante de uma das autoras. A observação participante foi feita em reuniões periódicas da coordenação do Programa ao longo de 2006 e início de 2007, às quais uma das autoras teve acesso por ter participado da implantação do ProJovem na cidade de São Paulo como representante da Secretaria Municipal do Trabalho e do Empreendedorismo, com a responsabilidade de desenvolver ações de qualificação profissional. O Quadro 1, a seguir, apresenta como o estudo foi realizado: 


\section{Quadro 1 - Estrutura da pesquisa}

\begin{tabular}{|c|c|c|}
\hline $\begin{array}{l}\text { Surgimento do } \\
\text { ProJovem em São } \\
\text { Paulo }\end{array}$ & $\begin{array}{l}\text { Compreender como o } \\
\text { Programa surgiu em } \\
\text { São Paulo }\end{array}$ & $\begin{array}{l}\text { Projeto Nacional do } \\
\text { ProJovem e convênio } \\
\text { celebrado entre Governo } \\
\text { Federal e Município de } \\
\text { São Paulo }\end{array}$ \\
\hline $\begin{array}{l}\text { Plano de } \\
\text { Implantação do } \\
\text { ProJovem em São } \\
\text { Paulo }\end{array}$ & $\begin{array}{l}\text { Descrever a proposta } \\
\text { de implantação } \\
\text { para cotejar com } \\
\text { os resultados da } \\
\text { implantação }\end{array}$ & $\begin{array}{l}\text {-Projeto de implantação } \\
\text { do ProJovem em São } \\
\text { Paulo } \\
\text { - Proposta de trabalho } \\
\text { do Cenpec } \\
\text { - Proposta de trabalho } \\
\text { do Cieds } \\
\text { - Proposta de trabalho } \\
\text { com a Fundação } \\
\text { Paulistana } \\
\text { - Press-release do } \\
\text { ProJovem em São Paulo } \\
\text { - Portaria intersecretarial } \\
\text { do ProJovem São Paulo }\end{array}$ \\
\hline $\begin{array}{l}\text { Implantação do } \\
\text { ProJovem no } \\
\text { Município. }\end{array}$ & $\begin{array}{l}\text { Descrever e analisar } \\
\text { a implantação do } \\
\text { Programa em São } \\
\text { Paulo }\end{array}$ & $\begin{array}{l}\text { Relatórios Gerenciais e } \\
\text { observação participante } \\
\text { nas reuniões da } \\
\text { coordenação municipal. }\end{array}$ \\
\hline
\end{tabular}

\section{Análise dos Dados}

Esta seção apresenta primeiramente um breve histórico do planejamento da implantação do ProJovem no município de São 
Paulo. Em seguida, o texto descreve a implementação do Programa no município e faz uma análise desse processo.

\subsection{O plano de implantação do ProJovem no município de São Paulo}

Em 2005, o Governo Federal, por meio do Fundo Nacional de Desenvolvimento da Educação (FNDE), assinou convênio com a Prefeitura Municipal de São Paulo para a implantação do ProJovem, com a meta de atender 30.000 jovens até 2006 .

O projeto de implantação previa as características que o Programa teria no Município, as formas de gestão, parcerias e outros aspectos apresentados a seguir.

Assim como no nível nacional, o Município adotou uma gestão compartilhada, no caso entre a Secretaria Municipal de Assistência e Desenvolvimento Social - SMADS, Secretaria Municipal de Educação - SME, Secretaria Municipal do Trabalho - SMTRAB e Secretaria Municipal de Participação e Parcerias SMPP, por meio da Coordenadoria Municipal da Juventude.

Além de definir as atribuições de cada pasta, o convênio criava uma estrutura organizacional no Município para a gestão do Programa, composta por um Comitê Gestor formado pelos secretários municipais, e uma Coordenação Municipal que seria responsável pela implantação do Programa no município. Cada Estação Juventude (denominação para os locais de aula), teria um coordenador, subordinado à Coordenação Municipal.

O modelo do ProJovem previa ainda a contratação de duas organizações sociais nas áreas de educação e ação comunitária para assessorar a Coordenação na execução do Programa. Uma das organizações contratadas seria responsável pela formação dos educadores e pelo acompanhamento pedagógico de suas ações. A segunda seria responsável pelo desenvolvimento das atividades de ação comunitária e pelo gerenciamento do cotidiano das Estações Juventude. 
De acordo com a meta acordada, o Município contaria com 25 Estações Juventude, cada uma com oito núcleos, totalizando 1.200 alunos por Estação. Para a instalação das Estações Juventude, seriam otimizados os equipamentos públicos municipais já existentes.

O plano de implantação previa a execução das atividades de acordo com as diretrizes estabelecidas pelo Governo Federal:

- A Coordenação Municipal comprometia-se a distribuir o material enviado pela Coordenação Nacional na primeira semana de aula.

- Os postos de matrícula seriam distribuídos por região, funcionando nos Centros de Referência de Assistência Social. O banco de dados seria encaminhado à Coordenação Municipal, após a leitura ótica e inserção dos dados no sistema eletrônico. Os coordenadores das Estações Juventude teriam a incumbência de acompanhar o registro dos dados sobre matrícula, frequência e aproveitamento dos jovens para que o repasse da bolsa auxílio fosse realizado, uma vez que a concessão da bolsa aos alunos estava condicionada à frequência mínima de $75 \%$ e à entrega de trabalhos. O pagamento seria feito diretamente pelo Governo Federal por meio de contas bancárias abertas em nome dos alunos na Caixa Econômica Federal, acessadas via cartão magnético.

- O Governo Federal encaminharia os computadores a serem utilizados nos laboratórios de informática à Coordenação Municipal, que ficaria encarregada de distribuir os equipamentos.

- O gerenciamento das Estações da Juventude caberia à SMADS, por meio da organização social contratada. Os núcleos seriam instalados em escolas da rede municipal de ensino.

- À Coordenação Municipal coube providenciar espaço e material adequados para a realização da etapa prática da qualificação profissional, que ocorreria no segundo semestre do curso. 


\subsection{A implementação do ProJovem em São Paulo}

A partir da assinatura do convênio com o Governo Federal, foram contratadas três organizações para executar as atividades previstas: o Centro de Estudos e Pesquisa em Educação, Cultura e Ação Comunitária (Cenpec) (para formação dos professores e o acompanhamento de suas ações pedagógicas), o Centro Integrado de Estudos e Programas de Desenvolvimento Sustentável (Cieds) (para seleção e atuação dos coordenadores, agentes de apoio e educadores de Ação Comunitária e apoio na implantação e acompanhamento cotidiano das Estações Juventude) e a Fundação Paulistana de Educação e Tecnologia (na contratação e remuneração de 1.000 professores de ensino fundamental e 200 educadores de qualificação profissional).

Em maio de 2006 foram iniciadas as aulas do ProJovem no município, com cerca de 500 alunos distribuídos em três Estações Juventude.

Os relatórios iniciais apontam dificuldades relacionadas às escolas que receberam o ProJovem. Algumas fechavam no período noturno, outras estavam em reforma e outras ainda estavam fechadas por conta do recesso escolar do meio do ano. Algumas não estavam distribuindo merenda aos alunos do ProJovem por falta de orientação da SME e/ou repasse de recursos. Em alguns núcleos, faltavam professores e educadores. Dificuldades também foram apontadas com relação ao desenvolvimento da perspectiva interdisciplinar proposta pelo Programa.

Em julho de 2006, representantes da Prefeitura de São Paulo reuniram-se em Brasília com representantes da Secretaria Geral da Presidência da República, para discutir os problemas desta fase inicial de implantação do Programa. A baixa quantidade de alunos matriculados, segundo a Prefeitura, devia-se a erros no cadastro, falta de recursos dos jovens para seu deslocamento e inadequação do perfil de alguns dos inscritos. Diante desses problemas, os representantes dos governos municipal e federal decidiram reabrir as matrículas e iniciar novas turmas, complementando tais providências com a realização de uma ampla campanha de 
divulgação voltada aos jovens inscritos e a busca de outros jovens com o perfil atendido pelo Programa.

De acordo com os relatórios, o sistema eletrônico de registro das matrículas apresentou falhas, por incompatibilidade técnica com os computadores da Prefeitura e por dificuldades de conexão com a internet.

Em agosto, iniciaram-se novas turmas, com a reabertura das matrículas e a intensificação do processo de divulgação. Foram abertas mais 11 Estações Juventude e o número de alunos com a frequência mínima exigida chegou a 5.000. Em outubro, foram iniciadas mais turmas desta primeira edição do ProJovem em São Paulo. Dessa forma, havia um grupo de turmas iniciadas em maio, outro em julho e finalmente um terceiro, em outubro. Durante todo o período inicial do Programa até novembro de 2006 estiveram abertas as inscrições. A intenção era atingir a lotação máxima das 14 Estações Juventude instaladas, o que significaria atingir cerca de 17 mil jovens.

As principais ocorrências registradas nos relatórios gerenciais de julho a dezembro de 2006 estão sistematizadas no quadro abaixo.

\section{Quadro 2 - Principais ocorrências dos relatórios gerenciais}

\begin{tabular}{|l|c|c|c|c|c|c|}
\hline \multicolumn{1}{|c|}{ Ocorrências/Meses } & Jul & Ago & Set & Out & Nov & Dez \\
\hline Atraso no pagamento da bolsa auxílio & $\mathrm{X}$ & $\mathrm{X}$ & $\mathrm{X}$ & $\mathrm{X}$ & & \\
\hline $\begin{array}{l}\text { Dificuldades para os alunos chegarem às } \\
\text { escolas por falta de } \\
\text { recursos }\end{array}$ & $\mathrm{X}$ & & $\mathrm{X}$ & & & \\
\hline Problemas com a merenda escolar & $\mathrm{X}$ & $\mathrm{X}$ & & & & \\
\hline $\begin{array}{l}\text { Escolas fechadas no período de recesso } \\
\text { escolar }\end{array}$ & $\mathrm{X}$ & & & & & \\
\hline $\begin{array}{l}\text { Falta de segurança no período noturno } \\
\text { nas escolas }\end{array}$ & $\mathrm{X}$ & & & & & \\
\hline Evasão de alunos & $\mathrm{X}$ & $\mathrm{X}$ & $\mathrm{X}$ & $\mathrm{X}$ & $\mathrm{X}$ & $\mathrm{X}$ \\
\hline
\end{tabular}


Limites e controvérsias da implantação...

\begin{tabular}{|c|c|c|c|c|c|c|}
\hline Realização de avaliação & $x$ & & & & & \\
\hline $\begin{array}{l}\text { Ações de combate à evasão e divulgação } \\
\text { do Programa }\end{array}$ & $x$ & $\mathrm{X}$ & $X$ & $x$ & $x$ & \\
\hline Ausência de alunos nas aulas & & $\mathrm{X}$ & $X$ & $x$ & & $x$ \\
\hline $\begin{array}{l}\text { Atraso no recebimento do material } \\
\text { didático }\end{array}$ & & $\mathrm{X}$ & & & & \\
\hline $\begin{array}{l}\text { Resistência da equipe escolar em aceitar } \\
\text { professores e alunos do ProJovem }\end{array}$ & & $x$ & & & & \\
\hline Entrega dos computadores nas escolas & & $x$ & $X$ & & & \\
\hline $\begin{array}{l}\text { Início da entrega de passe escolar } \\
\text { municipal aos alunos }\end{array}$ & & $x$ & & & & \\
\hline $\begin{array}{l}\text { Desenvolvimento de ações sociais } \\
\text { específicas de acordo com o perfil } \\
\text { dos alunos de alguns núcleos (jovens } \\
\text { grávidas, usuários de drogas) }\end{array}$ & & $\mathrm{X}$ & & & & \\
\hline $\begin{array}{l}\text { Matrícula de novos alunos e abertura de } \\
\text { novas turmas }\end{array}$ & & $\mathrm{x}$ & $X$ & $x$ & & \\
\hline $\begin{array}{l}\text { Dificuldades dos educadores } \\
\text { implementarem a proposta pedagógica } \\
\text { integrada }\end{array}$ & & $x$ & & $\mathrm{X}$ & & \\
\hline $\begin{array}{l}\text { Falta de educadores em algumas estações, } \\
\text { principalmente de educação profissional }\end{array}$ & & $\mathrm{x}$ & $X$ & $x$ & $x$ & \\
\hline $\begin{array}{l}\text { Dificuldades de instalação dos } \\
\text { computadores nas escolas (motivos: } \\
\text { espaço inadequado, rede lógica } \\
\text { inadequada, incompatibilidade de } \\
\text { sistemas, falta de orientação por parte da } \\
\text { SME, falta de segurança) }\end{array}$ & & & $X$ & $x$ & $x$ & $x$ \\
\hline Mudança de local de Estação Juventude & & & $\mathrm{X}$ & & & \\
\hline $\begin{array}{l}\text { Dificuldades para cumprir o calendário } \\
\text { de atividades (motivos: falta de } \\
\text { educadores, atraso na entrega do material } \\
\text { didático, alta rotatividade dos alunos) }\end{array}$ & & & & $x$ & & \\
\hline $\begin{array}{l}\text { Dificuldades na utilização do sistema } \\
\text { eletrônico }\end{array}$ & $x$ & & & & & \\
\hline
\end{tabular}




\begin{tabular}{|c|c|c|c|}
\hline $\begin{array}{l}\text { Dificuldades para planejar o início da } \\
\text { parte prática da qualificação } \\
\text { profissional (motivos: indefinição do } \\
\text { número de jovens e das datas) }\end{array}$ & $X$ & $x$ & $X$ \\
\hline $\begin{array}{l}\text { Atraso no início da parte prática da } \\
\text { qualificação profissional }\end{array}$ & & $x$ & \\
\hline
\end{tabular}

Fonte: Relatórios gerenciais ProJovem 2006 (Elaboração das autoras, 2012)

Os relatórios gerenciais, a pesquisa diagnóstica com os coordenadores de cada Estação Juventude e a participação na condução das atividades do Programa revelaram aspectos facilitadores e dificuldades recorrentes na implantação do ProJovem. Como principais aspectos facilitadores da gestão do Programa foram apontados: quadro de profissionais completo; comprometimento dos educadores com o Programa e com os alunos; bom funcionamento do sistema eletrônico e boas instalações nas Estações.

Por outro lado, foram identificados diversos obstáculos à implementação do Programa e ao cumprimento dos seus objetivos, como os problemas de comunicação do sistema de aferição da frequência, os atrasos no pagamento da bolsa auxílio e os prazos bancários para o processamento das contas, a emissão dos cartões e a organização interna do fluxo de pagamentos. Os atrasos no pagamento da bolsa auxílio foram causados pelo fato de muitos jovens não terem a documentação para abrir conta bancária. Já os prazos dos serviços bancários, por sua vez, nem sempre são adequados às necessidades de um programa de transferência de renda.

Houve baixo número de jovens matriculados e grande evasão de alunos. Os relatórios gerenciais apontam a taxa de evasão aproximada de 40\%, após 10 meses do início das aulas, com 3.008 alunos frequentes do total de 5.000. Todavia não foi possível obter a taxa final de evasão e existem contradições entre os números apresentados em diferentes relatórios. Esse resultado aponta para algumas questões: a dificuldade em encontrar e atrair 
esses jovens à escola, os problemas de cadastro e comunicação do sistema de informação, a superestimação de uma meta de atendimento de 30.000 jovens para atingir no máximo 5.000 jovens com a frequência exigida. No caso de São Paulo, muito se falou da inadequação do valor do benefício ( $\mathrm{R}$ \$ 100,00/mensais) para estimular a permanência e custear os gastos de deslocamento até a escola, tendo-se em vista o custo de vida na cidade. A instabilidade do Programa parece ter contribuído de forma considerável para a evasão dos alunos. Vale ressaltar que em outras capitais a meta proposta mostrou-se também muito acima da realidade.

A proposta pedagógica inovadora do ProJovem esbarrou em vários obstáculos para ser executada em uma estrutura pré-existente, com características e procedimentos próprios. Os conflitos que surgiram quando o Programa foi levado às escolas municipais demonstram essas dificuldades. As escolas não contavam, por exemplo, com infraestrutura adequada para suportar a instalação de computadores. Além disso, o atendimento aos jovens beneficiados pelo ProJovem gerou no cotidiano escolar situações prejudiciais às atividades programadas. Diretores, professores e alunos mostraram resistência ao Programa, incomodados pela necessidade de se oferecer merenda e material didático diferenciados para os alunos do ProJovem, bem como pela convivência, nas mesmas escolas, de alunos com e sem bolsa auxílio, além de professores com regimes de trabalho diferentes.

Também houve problemas relativos aos educadores do ProJovem, como absenteísmo, indisponibilidade causada pela jornada dupla de trabalho e incompatibilidade com a proposta metodológica. Segundo os relatórios, alguns professores apresentavam uma postura muito rígida e queixosa, sem compreender as limitações da Estação Juventude e do Programa, com resistência às propostas. Outros demonstravam preconceitos em relação aos alunos de alta vulnerabilidade social.

A precariedade de recursos também prejudicou o Programa, com a falta de material didático e de infraestrutura nos núcleos.

Outro ponto a ser destacado refere-se à implantação do Programa de forma simultânea à montagem da sua estrutura. 
A implantação das Estações Juventude, a contratação e capacitação dos profissionais, a inserção de dados no sistema informatizado, a preparação dos espaços para as aulas práticas de qualificação profissional foram atividades desenvolvidas no decorrer das aulas do Programa. Isso pode explicar algumas outras dificuldades observadas, na medida em que essa estrutura diferenciada dependia de um aprendizado prévio por parte dos atores encarregados de colocá-la em funcionamento.

A intersetorialidade do Programa trouxe desafios tanto em nível nacional quanto municipal. A articulação necessária entre as diferentes secretarias nem sempre ocorreu, devido a problemas de comunicação e gestão. A Secretaria Municipal de Assistência e Desenvolvimento Social buscou liderar o Programa e envolver todas as outras secretarias, inserindo o ProJovem na agenda municipal. Com o passar do tempo, porém, as demais secretarias começaram a se desmobilizar diante dos recorrentes problemas no desenvolvimento do Programa.

A Secretaria de Educação, inicialmente bastante proativa, enfrentou dificuldades na instalação dos computadores e na adaptação da rotina das escolas ao ProJovem. A Fundação Paulistana, responsável pelo pagamento dos professores, teve problemas com a atualização do sistema e demonstrou não ter capacidade para gerenciar a folha de pagamento de um programa com o ProJovem. Diante disso, umas das resoluções da pasta foi não dar continuidade a outras turmas após o término daquela edição. Buscando aplicar o que aprendera com a experiência, passou a desenvolver ações para esse público dentro da sua própria estrutura e de acordo com suas próprias diretrizes.

A Secretaria do Trabalho, por sua vez, não conseguiu realizar satisfatoriamente a adequação de espaços e a compra de insumos para as aulas práticas de qualificação profissional. A constante evasão de alunos impedia que se tivesse um número definido de beneficiários e assim poder contratar os serviços e comprar os produtos com antecedência. Como resultado, as aulas de qualificação foram dadas em sua maioria em locais improvisados 
e contando com a boa vontade e iniciativa de educadores e profissionais das Estações e da Secretaria.

Finalmente, a Secretaria de Participação e Parceria, por meio da Coordenadoria da Juventude, foi ator pouco participante, distanciando-se das ações do Programa no decorrer de sua implantação. Esse pode ser um dos motivos pelos quais a implantação do Programa não contou com a participação dos próprios jovens, como estava previsto, já que essa Secretaria tinha a incumbência de divulgar o ProJovem e mobilizar os jovens.

A diferença partidária entre governo federal (PT) e governo municipal (PSDB) não apareceu como elemento a ser considerado nos problemas enfrentados na fase inicial de implantação do ProJovem. Contudo, outros levantamentos precisariam ser realizados para defender qualquer afirmação no sentido.

Como apontado por Majone e Wildavsky (1995), na implantação de uma política pública ocorre aprendizagem, evolução, adaptação e decisão. Contudo, no caso da implantação do ProJovem no Município de São Paulo, sequer houve tempo para o aprendizado. Discutiu-se posteriormente ao inicio do Programa se não deveria ter havido uma experiência piloto a partir da qual ele pudesse se expandir. Uma proposta carregada de tanta inovação requeria um tempo maior de estudo e preparação. De acordo com Sposito (2003), iniciativas como o ProJovem, embora deem espaço à inovação e experimentação, resultam em pouca efetividade e enfraquecem uma política pública integrada e mais ampla.

A primeira edição do ProJovem foi concluída graças ao empenho dos técnicos das secretarias e Estações da Juventude. Não conseguimos obter informações sobre o número de alunos formados, mas sabe-se que a evasão foi constante e considerável ao longo de todo o Programa. Certamente, foram prejudicados a efetividade do Programa e o aproveitamento dos estudantes, principalmente das primeiras turmas, que sofreram diversas descontinuidades. 
Segundo informações do site da Prefeitura de São Paulo, houve um turma do ProJovem Trabalhador em 2010, formando 1.663 jovens (SÃO PAULO SITE, 2013). Segundo site do ProJovem, São Paulo é um dos municípios que o implementa atualmente.

O ProJovem continua em andamento em nível nacional. Foram feitas reformulações e hoje o Programa tem características diferentes, como a divisão entre ProJovem Trabalhador e ProJovem Adolescente, discutido anteriormente.

\section{Considerações Finais}

O presente estudo permitiu identificar que é também na implantação de um plano que ele se faz. A política é redesenhada no momento em que ela acontece. No caso específico do ProJovem no município de São Paulo, notam-se os seguintes reajustes: a reabertura de matrículas, a realização de nova campanha de divulgação para os jovens inscritos e a busca de novos jovens, o desenvolvimento de atividades específicas tendo em vista o perfil dos alunos (jovens grávidas, usuários de drogas), entre outros. Todavia, o aprendizado necessário para a implementação do Programa era muito mais amplo e não houve tempo para que se completasse.

Diante dos problemas da fragmentação e da falta de participação da sociedade civil nas políticas de juventude, o governo Lula buscou implementar uma ação unificada, criando um programa e uma secretaria específicos, mas não conseguiu superar os limites observados nessas políticas durante governos anteriores. Segundo Sposito, Silva e Sousa (2006), os problemas relacionam-se com a baixa capacitação técnica dos instrutores, a base material precária, a falta de participação dos jovens e a necessidade de atuação na comunidade.

Espera-se que o jovem promova o desenvolvimento do seu bairro, quando o Estado e outras instituições não o fizeram. Por que essas exigências e expectativas em relação apenas aos jovens 
pobres? É como se eles, quejá não conseguem ter a mínima estrutura material, psicológica e social para, por exemplo, permanecerem na escola, devessem atuar na comunidade. Os autores questionam o fato de alunos de escolas técnicas ou universidades públicas não estarem também submetidos à contrapartida comunitária, sabendo-se que teriam melhor capital cultural e social para isso. (SPOSITO; SILVA; SOUSA, 2006, p. 255).

O estigma do jovem como questão social ainda permanece, já que a opção do governo foi focar em jovens marginalizados, separando-os dos outros jovens. Como podemos notar, problemas foram enfrentados pelo ProJovem em relação às diferenciações entre os jovens atendidos e os demais alunos das escolas onde o Programa era executado.

A participação do público jovem na implantação do ProJovem foi praticamente nula. Os interessados não foram ouvidos e não puderam apresentar sugestões para corrigir falhas do Programa. É possível que, com um caráter mais participativo, o Programa fosse mais atraente para os jovens e tivesse melhores condições para sua continuidade em São Paulo.

O perfil dos professores é um dos aspectos apontados negativamente nos relatórios gerenciais. Eles podem ser considerados como exemplos de burocratas de nível de rua, cuja influência na implantação de políticas públicas já foi amplamente pesquisada (LOTTA, 2010). Neste sentido observaram-se, sobretudo entre os professores do ensino fundamental, uma postura resistente à proposta do Programa e dificuldades para lidar com o público de alta vulnerabilidade. Por outro lado, nos educadores de qualificação profissional e ação comunitária, observou-se maior facilidade de lidar com os alunos, participação na proposta do Programa e contribuição para o desenvolvimento das atividades mesmo quando não se conseguia a estrutura necessária.

A base material permaneceu precária no ProJovem, como se, mesmo atuando intersetorialmente, o Programa não tivesse incorporado as lições trazidas pelos erros das políticas anteriores. Tal deficiência comprometeu estruturalmente seus resultados. 
É nesse contexto que propomos a realização de novas pesquisas para analisar a repetição desses erros. A recorrência dessas falhas pode ser causada pelo fato de as políticas públicas específicas para juventude ainda serem recentes, sem um tempo de maturação suficiente para incorporar aprendizado. Outra hipótese é que os problemas sejam decorrentes da baixa articulação dos programas anteriores, o que teria impedido a disseminação das lições aprendidas com as primeiras experiências. Há também a possibilidade de que não só o estigma que costuma ser atribuído ao jovem, principalmente ao jovem pobre, como também o desenho estereotipado da política para esse público seja replicado sem questionamento, bloqueando o diálogo e a participação. Uma das possíveis consequências disso seria o descompasso entre o formato das ações de capacitação profissional previstas no Programa e as reais necessidades dos jovens. Por fim, outra possibilidade é a da política pública não ter incluído os jovens para discutir as próprias políticas, de modo a torná-las mais efetivas.

Essas questões são cruciais para uma discussão mais ampla sobre as práticas que deram resultados positivos, bem como sobre as dificuldades na implantação das políticas públicas para a juventude, a fim de que possamos produzir políticas mais efetivas.

\section{Bibliografia}

BRASIL. Ministério da Educação. Conselho Nacional de Educação. Parecer CNE/CEB 2/2005. ProJovem - Programa Nacional de Inclusão de Jovens: Educação, Qualificação e Ação Comunitária. Brasília: março, 2005. Disponível em: <http://migre.me/e85zu> Acesso em: 15 abr. 2013.

BRASIL. Projeto Pedagógico Integrado do ProJovem Urbano. Brasília, maio de 2008. Disponível em: www.ProJovem.gov.br/ userfiles/file/SET\%202008_\%20PPI\%20FINAL.pdf Acesso em: 01 mai. 2013. 
GODOY, A. "Pesquisa Qualitativa: tipos fundamentais." Revista de Administração de Empresas, v. 35, n. 3, p. 20-29, maio/jun. 1995.

GRINDLE, Merilee. "Implementing reform: arenas, stakes and resources." In: GRINDLE, Merilee; THOMAS, John. Public choice and policy change. Maryland, Baltimore: The Johns Hopkins University Press, 1991.

LIPSKY, Michael. Street-level Bureaucracy; Dilemmas of the Individual in Public Service. New York: Russel Sage Foundation, 1980.

LOPES, Roseli Esquerdo; SILVA, Carla Regina; MALFITANO, Ana Paula Serrata. "Adolescência e juventude de grupos populares urbanos no Brasil e as políticas públicas: apontamentos históricos." Revista HISTEDBR On-line, n. 23, p. 114-130, set. 2006.

LOTTA, Gabriela S. Implantação de políticas públicas: o impacto dos fatores relacionais e organizacionais sobre a atuação dos burocratas de nível da rua no Programa Saúde da Família. São Paulo: Universidade de São Paulo/FFLCH, Tese de Doutorado, 2010. Cap. 1, p. 25-51.

MAJONE, Giandomenico; WILDAVSKY, Aaron. "Implementation as evolution." In: THEODOULOU, Stella; CAHN, Matthew A. Public Policy: the essential readings. Upper Saddler River, NI: Prentice Hall, 1995.

MATIAS-PEREIRA, J. Manual de Metodologia da Pesquisa Científica. 1a. ed. São Paulo: Editora Atlas S.A., 2007. v. 2000. p. 160.

SÃO PAULO (Cidade). Prefeitura Municipal de São Paulo. Projeto de implantação do ProJovem no município de São Paulo. São Paulo: 2005. Cópia impressa.

SÃO PAULO SITE Prefeitura Municipal de São Paulo. Disponível em: http://www.capital.sp.gov.br/portalpmsp/ homec.jsp. Acesso em: 01/05/2013. 
SARAIVA, Enrique. 2006. "Introdução à teoria da política pública." In: SARAIVA, Enrique; FERRAREZI, Elisabete. (Orgs.). Políticas públicas. Brasília: ENAP, 2006.

SILVA, Pedro Luiz Barros; MELO, Marcus André Barreto de. "O processo de implantação de políticas públicas no Brasil: características e determinantes da avaliação de programas e projetos". Caderno n. 48. Unicamp - Núcleo de Estudos de Políticas Públicas: Campinas, 2000.

SOUZA, Celina. "Políticas Públicas: uma revisão da literatura". Sociologias. Porto Alegre, n. 16, p. 20-45, jul/dez 2006.

SPOSITO, Marília Pontes. Os jovens no Brasil: desigualdades multiplicadas e novas demandas políticas. São Paulo: Ação Educativa, 2003.

SPOSITO, Marília Pontes; CARRANO, Pedro César Rodrigues. "Juventude e políticas públicas no Brasil." Revista Brasileira de Educação, n. 24, p. 16-39, 2003.

SPOSITO, Marília Pontes; SILVA, Hamilton Harley de Carvalho; SOUZA, Nilson Alves de. "Juventude e poder local: um balanço de iniciativas públicas voltadas para jovens em municípios de regiões metropolitanas". Revista Brasileira de Educação, v. 11, n. 32, p. 238-257, 2006. 